\title{
It's time to focus on autonomic function after spinal cord injury
}

\author{
Marcalee Alexander ${ }^{1,2,3}$
}

Received: 16 October 2017 / Accepted: 17 October 2017

(c) International Spinal Cord Society 2017

Spinal cord injuries cause a myriad of complications on top of the obvious paralysis and loss of sensation. However, the recovery and related morbidities associated with motor and sensory function after SCI has received substantially more attention than the recovery of autonomic function. In 2009. the International Standards for the Recovery of Autonomic Function after SCI (ISAFSCI) were first published [1] as a means to standardize documentation about the impact of SCI on autonomic responses. These standards were revised in 2012 [2] and are currently being reviewed for a 2nd revision.

As Editor-in-Chief of Spinal Cord Series and Cases, I am especially interested in highlighting reports related to autonomic concerns of persons with SCIs. Additionally, I would like to make the use of the standards required for papers submitted to SCSC around 2019.

As part of this initiative over the next few weeks a series of reports will be published related to specific aspects of autonomic function after SCI. These papers will highlight the use of various components of the standards and nuances of utilizing them. These standards were also discussed at a special interest meeting on the 25th of October at the ISCOS meeting in Dublin.

I hope you will enjoy reading these articles and the issues they bring up. Of particular interest is the issue of thermodysregulation discussed by Handrakis et al. and how rising temperatures around the world will impact persons with SCIs, especially in developing countries. Additionally, the utility of the ISAFSCI for predicting the remaining control of bladder, bowel, and sexual concerns and coordinating use of the standards and data sets is important to consider.

Additional articles and ideas related to these important topics are highly desired. Remember, Series and Cases wants your new ideas and opinions. This is the place to plant the seeds of new ideas related to SCI!

\section{Compliance with ethical standards}

Conflict of interest The authors declare that they have no competing interests.

\section{References}

1. Alexander MS, Biering-Sorensen F, Bodner D, Brackett NL, Cardenas D, Charlifue S, et al. International standards to document remaining autonomic function after spinal cord injury. Spinal Cord. 2009;47:36-43.

2. Krassioukov A, Biering-Sorensen F, Donovan W, Kennelly M, Kirshblum S, Krogh K, et al. International standards to document remaining autonomic function after spinal cord injury. J. Spinal Cord Med. 2012;35:201-10.
Marcalee Alexander

spinalcordmd@live.com

1 Department of Physical Medicine and Rehabilitation University of Alabama at Birmingham School of Medicine, Birmingham, Alabama, USA

2 Department of Physical Medicine and Rehabilitation Harvard School of Medicine, Boston, Massachusetts, USA

3 Birmingham VA Medical Center, Birmingham, Alabama, USA 